\section{As múltiplas facetas do processamento da leitura em indivíduos afásicos: revisão de literatura}

Multiple facets of reading processing in aphasic individuals: literature review

Sabrine Amaral MARTINS (PUCRS) sabrine.martins@acad.pucrs.br
MARTINS, Sabrine Amaral. As múltiplas facetas do processamento da leitura em indivíduos afásicos: revisão de literatura. Entrepalavras, Fortaleza, v. 6, n. 2, p. 370-390, jul./ dez. 2016.

Resumo: A afasia é uma perturbação linguística relativamente comum. Ela acomete os pacientes que sofreram acidente vascular encefálico. No nível linguístico, é considerada um prejuízo nos componentes dos sistemas semântico, sintático, fonológico e morfológico. Múltiplos aspectos da comunicação são prejudicados. Todos os tipos e níveis de afasia apresentam problemas na leitura. Embora alguns trabalhos foquem nos déficits de leitura provenientes da afasia, muito pouco se sabe. Por isso, este trabalho tem o objetivo de apresentar dados de investigações sobre esse tema. O presente trabalho justifica-se por contribuir para um maior aprofundamento no tema estudos em afasia no Brasil.

Palavras-chave: Afasia. Acidente vascular encefálico. Leitura. 
Abstract: Aphasia is a common linguistic disorder. It occurs in stroke patients. At the linguistic level, it is considered a damage on the semantic, syntactic, phonological and morphological systems components. Many aspects of communication may be damaged. It is known all types and levels of aphasia present problems in reading. Although there is some research focusing on the on reading deficits and aphasia, little is known. This is the main reason of this work. It aims to present data from investigations of reading and aphasia. This it contributes to a wider view about the topic of aphasia in Brazil.

Keywords: Aphasia. Stroke. Reading.

\section{Introdução}

As doenças cerebrovasculares estão incluídas nas causas prevalecentes de internações hospitalares no Brasil, impactando sob a saúde pública. O Acidente Vascular Encefálico (AVE) ou derrame, como é popularmente conhecido, é derivado de uma obstrução ou de uma ruptura de um vaso sanguíneo responsável por nutrir parte de um hemisfério cerebral (KANDEL, SCHWARTZ, JESSEL, 2000), dando início a uma falta de oxigenação ou uma hemorragia naquele local. $\mathrm{O}$ AVE, também denominado acidente vascular cerebral - AVC, de acordo com estatísticas, é a segunda razão da morte em adultos no Brasil. Os distúrbios de linguagem ocorrem em aproximadamente $25 \%$ desses casos (ORTIZ, 2010). Um exemplo de distúrbio é a afasia, descrita como uma diminuição e uma disfunção da linguagem que se manifesta com graus variados de comprometimento tanto na modalidade expressiva (fala ou escrita), quanto na receptiva (leitura e compreensão oral), gerando um acometimento significativo na vida social e profissional dos indivíduos (ORTIZ, 2010). Como esse distúrbio compromete de forma expressiva a qualidade de vida dos indivíduos, é importante atentar para fatores que possam influenciar em uma possibilidade de aumento da qualidade de vida, como a leitura. A preservação ou manutenção da habilidade de leitura permitiria que os indivíduos com afasia possuam mais oportunidades de tratamentos, bem como mais opções de atividades de lazer. Refletindo sobre esse aspecto, o presente trabalho pretende apresentar dados de uma revisão de pesquisas sobre o processamento da leitura na afasia. Para tanto, foi reaizada uma pesquisa bibliográfica nas bases de dados Lilacs, ScienceDirect, Scopus, Web of Science e PubMed. A presente revisão justifica-se por contribuir para um maior aprofundamento no assunto, mostrando múltiplas facetas do tema, com o intuito também de mais amplamente disseminar estudos sobre afasia no Brasil, tópico que precisa ser alvo de maior investigação. 
v. $6(2)$

$370-390$

jul/dez

2016

Para dar início à discussão sobre o status da afasia e leitura no país, é preciso conceituar o que os estudiosos entendem por afasia, bem como algumas classificações. Além disso, também serão abordadas características apresentadas pela leitura dos indivíduos afásicos. Logo, a seção 2, a seguir, e as suas respectivas subseções são importantes para uma reflexão preliminar sobre o tema.

\section{Afasia e leitura}

Sequelas linguísticas graves podem advir dos AVEs, tais como dificuldades na produção e compreensão da linguagem. As dificuldades na produção oral podem tratar-se da incapacidade de nomeação de objetos, de identificação das letras do alfabeto, dentre outras. Já as dificuldades de compreensão referem-se a problemas no reconhecimento de palavras soltas, entendimento de mapas e sinais de trânsito, compreensão de narrativas no nível superficial, por exemplo. As dificuldades na leitura podem influenciar a habilidade de ler um jornal e/ou selecionar palavras, usar um índice, leitura em voz alta e escrita em geral (ORTIZ, 2010). Todas as sequelas dos AVEs e, principalmente, o prejuízo linguístico, como a afasia, podem impactar a vida em sociedade. No Brasil, 38\% das pessoas com AVE apresentam afasia na fase aguda e 20\% das vítimas continuam com alguma alteração de linguagem após seis meses do ocorrido (LIMA, 2009; MANSUR et al., 2002). Para entender um pouco mais sobre a gravidade desse problema, considerado de saúde pública, e sua relação com a leitura, segue a definição do que é a afasia.

Definição de afasia

A afasia pode ser caracterizada como uma alteração no conteúdo, na forma e no uso da linguagem e de seus processos cognitivos subjacentes, tais como percepção e memória (SPRINGER, 2008). Atualmente, ela é classificada em fluente e não fluente. A afasia fluente (também chamada de receptiva ou sensória) refere-se ao input ou recepção da linguagem, seguida de dificuldades de compreensão, mas com output linguístico praticamente sem esforço. Entre seus tipos estão: Afasia de Wernicke, Sensória Transcortical, de Condução e Anômica. A afasia fluente é marcada por uma taxa normal de discurso desprovido de hesitações ou pausas, porém um discurso de muito difícil 
entendimento. No caso da Afasia de Wernicke ${ }^{1}$, em particular, há um excesso de discurso fluente e espontâneo, de estruturas sintáticas longas e complexas com velocidade, articulação e entonação normais, no entanto, trata-se de um discurso completamente sem sentido e repleto de parafasias ${ }^{2}$, neologismos, pseudopalavras, hesitações, circunlóquios, problemas para encontrar palavras e dificuldade em fazer repetições de palavras e/ou frases (AKBARI, 2014). Já nas afasias não fluentes acontece uma fala e uma escrita truncada, centrada em palavras de conteúdo em detrimento das funcionais, acompanhada eventualmente de problemas no nível morfológico, geralmente identificados pela falta de conjugação verbal ou por problemas nas flexões de substantivos e escolhas de determinantes.

De acordo com Akbari (2014, p.123), na afasia, "todas as atribuições do sistema linguístico podem ser afetadas, em níveis de acometimento distintos". Em alguns casos,

pode haver o comprometimento de certos componentes ou modalidades da língua ou de todos os níveis linguísticos, incluindo a fonologia, o léxico, a morfologia, a sintaxe e a semântica e também o discurso (AKBARI, 2014, p.124).

O déficit de compreensão é uma das habilidades que podem ser prejudicadas com a ocorrência da afasia. Tanto a compreensão leitora quanto a compreensão auditiva ${ }^{3}$ podem ser afetadas. Ortiz (2010) aponta que, nos diferentes tipos de afasias, a compreensão pode estar danificada em níveis distintos tal qual a produção oral. Nas afasias não fluentes, de Broca e de condução, por exemplo, há dificuldade em compreender frases complexas, textos e elementos gramaticais. Já nas fluentes, como a de Wernicke e a transcortical sensorial, há déficits de compreensão auditiva e leitora, sendo que esta última pode estar tão comprometida quanto a auditiva. Há muito o que ser investigado sobre a leitura na afasia. Moineau (2005) aponta que, apesar de haver muitas evidências empíricas sobre os prejuízos advindos da afasia, as suas definições e caracterizações de seus subtipos continuam bastante modulares.

1 Também conhecida como paragramatismo por envolver a omissão ou substituição assistemática de afixos morfológicos que alteram o significado de uma proposição, possivelmente ao ponto de torná-la incoerente (AKBARI, 2014).

2 Substituições e omissões de palavras e fonemas.

3 Neste trabalho adota-se a nomenclatura compreensão leitora e compreensão auditiva, embora haja outras denominações para essas habilidades, como: compreensão de texto, escrita e gráfica equivalendo à compreensão leitora, ou compreensão oral equivalendo à auditiva. 
v. $6(2)$

$370-390$

$\mathrm{jul} / \mathrm{dez}$

2016

Todavia, há dados em abundância sugerindo que esses déficits podem estar em um continuum, tanto das habilidades menos para as mais prejudicadas, quanto dos componentes linguísticos indissociáveis de outros construtos cognitivos, como atenção e memória de trabalho. Muito do que é sugerido por Moineau; Dronkers; Bates (2005) foi encontrado na presente revisão.

\section{A leitura na afasia}

Normalmente as investigações que abordam a leitura atentam para o processamento das palavras e das frases no acometimento. O estudo de Purdy e Newman (2011) compara a performance de indivíduos com afasia fluente e não fluente em 19 subtestes da bateria Psycholinguistic Assesments of Language Processing in Aphasia (PALPA, de KAY; LESSER; COLTHEART, 1992). Os pacientes que possuem afasia não fluente foram bem-sucedidos nas tarefas de decisão auditiva e lexical, mas não nas tarefas fonológicas; ou seja, os participantes com afasias fluentes demostraram prejuízos nas tarefas lexicais e tiveram escores variados nas tarefas de leitura de palavras e não-palavras. Já a pesquisa de Kim e Bolger (2012) investigou o efeito do contexto semântico no rastreamento ocular em afásicos e controles durante a leitura de frases. Os movimentos oculares dos afásicos diferiram significativamente em relação ao dos controles, os quais foram mais eficientes quando liam frases mais contextualizadas. Além disso, foi observado que o processamento top-down facilitou a leitura. Ainda, o estudo de McNeil e colegas (2015) comparou as compreensões leitora e auditiva de afásicos com as de controles no Revised Token Test (RTT, de McNEIL; PRESCOTT, 1978). Eles trabalharam nos níveis da palavra e da sentença. Concluiuse que as diferenças nas intermodalidades foram pequenas e sensíveis aos prejuízos advindos da afasia. Por consequência dessa variedade de dados sobre a leitura na afasia, é que pesquisas na área se fazem tão importantes. Para tal, uma abordagem sobre as características da leitura afásica se faz necessária.

As características da leitura afásica

As limitações provenientes do transtorno podem ser tão sérias a ponto de deixar a comunicação com o afásico muito dificultosa. A afasia pode afetar a habilidade de lembrar nomes de objetos, a habilidade de organizar as palavras nas frases ou a habilidade de leitura. Normalmente, 
vários aspectos da comunicação são fragilizados. Sabe-se que todos os tipos e níveis de afasia têm problemas de leitura. Ao passo que alguém com anomia - dificuldade de nomeação de objetos - pode ter danos na leitura de livros, a pessoa com afasia severa pode apenas reconhecer algumas palavras. Dentre os prejuízos mais comuns na leitura, podem estar: problemas em entender substantivos ou palavras de conteúdo e função, reconhecer palavras soltas, ler um jornal e selecionar palavras, entender mapas, sinais de trânsito. Há ainda problemas em identificar as categorias dos objetos, por exemplo, onde encontrar determinado produto no supermercado. Ainda, os problemas na leitura de narrativa seguem do nível mais superficial até o mais profundo. Os afásicos têm dificuldade em memorizar fatos de uma narrativa após a leitura de um parágrafo; da mesma forma, têm problemas na abstração e interpretação daqueles textos muito longos, além de dificuldade de leitura em voz alta, nomeação das letras do alfabeto e resumo. Enfim, muitos são os déficits observados nesse distúrbio. A seguir, os artigos sobre esses problemas com suas principais contribuições.

\section{Método}

Esta pesquisa bibliográfica pretende apresentar dados de uma revisão sistemática de estudos sobre a leitura na afasia. Foi realizada uma investigação nas bases de dados Lilacs, ScienceDirect, Scopus, Web of Science e PubMed. Foram utilizados 23 artigos, datados de 2005 a 2015, publicados em português ou inglês, a partir dos indexadores <afasia>, <afásico> <leitura>, <compreensão leitora>. As palavras indexadoras podiam aparecer nos títulos dos artigos ou nos resumos ou abstracts. São analisados apenas artigos que tratam de lesões circunscritas ao hemisfério esquerdo. Ao todo, após observados os critérios de exclusão, foram selecionados 13 artigos.

$\mathrm{Na}$ base de dados Lilacs, foram encontrados mais de 2000 textos tratando de afasia. Ao aplicar os filtros, restringindo o período temporal, excluindo as revisões, teses e outras publicações que não fossem artigos, foram encontrados 526 textos. A partir de uma leitura detalhada dos títulos e resumos, pode-se selecionar 6 textos. Após uma leitura dos textos na íntegra, apenas 2 artigos mostraram-se relevantes para a revisão.

Na base de dados ScienceDirect, foram achadas 12.233 referências. A partir dos filtros disponibilizados na própria base de dados, como 
v. 6 (2)

$370-390$

$\mathrm{jul} / \mathrm{dez}$

2016

o filtro de período temporal, tipo de texto e assunto, chegou-se a um montante de 317 textos. Após uma leitura detalhada dos títulos e resumos, pode-se selecionar 2 pesquisas interessantes para esta revisão. Destaca-se que muitos dos artigos encontrados relatavam sobre afasia bilíngue, fator descartado pelos critérios.

A base SCOPUS localizou 488 textos sobre afasia. Nos resultados, o sistema identificou 445 como artigos que possuíam os indexadores <afasia>, <afásico> <leitura>, <compreensão leitora> no título ou no resumo. Portanto, foi necessária uma leitura desses títulos e resumos para a seleção dos 3 restantes.

Na base Web of Science, o filtro de línguas foi usado, visto que as opções eram em inglês e/ou coreano. Foram encontrados 493 textos sobre afasia, dentre os quais 2 eram sobre leitura e afasia. Tanto a Web of Science quanto a SCOPUS apresentaram inúmeros textos que já haviam sido citados pelas bases de dados pesquisadas anteriormente. Portanto, alguns dos textos fornecidos por estas bases não foram utilizados porque já constavam na pesquisa bibliográfica.

Na PubMed, resultaram 815 artigos. Todavia, somente um montante de 406 desses artigos eram do período especificado. A partir de uma leitura dos resumos, 4 textos foram selecionados e lidos. Seguem abaixo os resultados com a tabela-resumo dos textos.

\section{Resultados}

Após uma leitura avaliativa dos 13 textos encontrados nas bases acima, fez-se necessário construir um quadro-resumo com os objetivos e resultados dessas pesquisas. Destaca-se que, dentre os artigos, apenas 2 tiveram suas pesquisas realizadas no Brasil. Os títulos dos artigos foram mantidos em seu idioma original, visto que, em algumas bases, não é possível localizá-los em língua portuguesa. Segue abaixo o quadro. 
Quadro 1 - Artigos utilizados na revisão com suas respectivas características

\begin{tabular}{|c|c|c|c|}
\hline Título & Autores & Objetivo & Resultado \\
\hline $\begin{array}{l}\text { Introdução da } \\
\text { comunicação } \\
\text { suplementar e } \\
\text { alternativa na } \\
\text { terapia com } \\
\text { afásicos }\end{array}$ & $\begin{array}{l}\text { GALLI; OLIVEIRA; } \\
\text { DELIBERATO } \\
\text { (2009) }\end{array}$ & $\begin{array}{l}\text { Descrever o uso } \\
\text { da comunicação } \\
\text { suplementar } \\
\text { e alternativa } \\
\text { associada a outras } \\
\text { modalidades de } \\
\text { linguagem (escrita, } \\
\text { gestos), a partir } \\
\text { do relato de dois } \\
\text { casos de afasia. }\end{array}$ & $\begin{array}{l}\text { A comunicação } \\
\text { suplementar e } \\
\text { alternativa foi } \\
\text { um apoio para a } \\
\text { oralidade, leitura } \\
\text { e escrita dos } \\
\text { pacientes. }\end{array}$ \\
\hline $\begin{array}{l}\text { Aplicação do } \\
\text { teste M1-Alpha } \\
\text { em sujeitos } \\
\text { normais com baixa } \\
\text { escolaridade: } \\
\text { estudo piloto }\end{array}$ & $\begin{array}{l}\text { ORTIZ; COSTA } \\
(2011)\end{array}$ & $\begin{array}{l}\text { Verificar o } \\
\text { desempenho de } \\
\text { sujeitos normais } \\
\text { com baixa } \\
\text { escolaridade no } \\
\text { teste M1-Alpha e } \\
\text { obter parâmetros } \\
\text { que possam ser } \\
\text { utilizados na } \\
\text { avaliação clínica } \\
\text { de pacientes } \\
\text { afásicos com baixa } \\
\text { escolaridade. }\end{array}$ & $\begin{array}{l}\text { A baixa } \\
\text { escolaridade } \\
\text { influencia o } \\
\text { desempenho dos } \\
\text { indivíduos nas } \\
\text { tarefas de escrita } \\
\text { copiada, ditado, } \\
\text { leitura em voz alta } \\
\text { e compreensão } \\
\text { escrita. }\end{array}$ \\
\hline $\begin{array}{l}\text { Stress assignment } \\
\text { in aphasia: Word } \\
\text { and non-word } \\
\text { Reading and non- } \\
\text { word repetition }\end{array}$ & $\begin{array}{l}\text { BREE; JANSE; } \\
\text { ZANDE (2007) }\end{array}$ & $\begin{array}{l}\text { Investigar a } \\
\text { atribuição do } \\
\text { acento tônico } \\
\text { em afásicos na } \\
\text { não-repetição de } \\
\text { palavras e a não } \\
\text { leitura de palavras. }\end{array}$ & $\begin{array}{l}\text { Os erros dos } \\
\text { pacientes } \\
\text { sugerem que há } \\
\text { um problema na } \\
\text { retenção dos alvos } \\
\text { que possuem } \\
\text { irregularidades }\end{array}$ \\
\hline $\begin{array}{l}\text { Oral reading } \\
\text { and Writing in } \\
\text { Broca's aphasia: } \\
\text { Implications for } \\
\text { the common and } \\
\text { Independent } \\
\text { Lexicon theories }\end{array}$ & $\begin{array}{l}\text { BALASUBRA } \\
\text { MANIAN; } \\
\text { COSTELLO (2011) }\end{array}$ & $\begin{array}{l}\text { Testar as previsões } \\
\text { da Teoria do Léxico } \\
\text { Independente } \\
\text { em uma análise } \\
\text { compreensiva } \\
\text { da leitura oral } \\
\text { e escrita de um } \\
\text { afásico de Broca } \\
\text { com dislexia } \\
\text { profunda. }\end{array}$ & $\begin{array}{l}\text { A leitura e a escrita } \\
\text { do paciente foram } \\
\text { influenciadas } \\
\text { pela Teoria, no } \\
\text { entanto, não } \\
\text { existem teorias } \\
\text { que abordem o } \\
\text { efeito de demora } \\
\text { nas substituições } \\
\text { semânticas na } \\
\text { escrita. Portanto, } \\
\text { ainda é precoce } \\
\text { assumir que a } \\
\text { TLI pode ser } \\
\text { evidenciada por } \\
\text { este caso. }\end{array}$ \\
\hline
\end{tabular}




\begin{tabular}{|c|c|c|c|}
\hline $\begin{array}{l}\text { Evaluation of } \\
\text { attention training } \\
\text { and metacognitive } \\
\text { facilitation to } \\
\text { improve reading } \\
\text { comprehension in } \\
\text { aphasia. }\end{array}$ & $\begin{array}{l}\text { LEE; SOHLBERG, } \\
(2013)\end{array}$ & $\begin{array}{l}\text { Investiga o } \\
\text { impacto da atenção } \\
\text { na compreensão } \\
\text { leitora dos } \\
\text { afásicos. }\end{array}$ & $\begin{array}{l}\text { Intervenções } \\
\text { que incluem } \\
\text { treinamento da } \\
\text { atenção podem } \\
\text { aprimorar a } \\
\text { performance dos } \\
\text { participantes. }\end{array}$ \\
\hline $\begin{array}{l}\text { Real-time } \\
\text { processing in } \\
\text { Reading sentence } \\
\text { comprehension } \\
\text { for normal adult } \\
\text { individuals and } \\
\text { persons with } \\
\text { aphasia }\end{array}$ & SUNG et al. (2011) & $\begin{array}{l}\text { Investigar o } \\
\text { nível da frase } \\
\text { pela categoria de } \\
\text { palavra adjetivo } \\
\text { enquanto ela é } \\
\text { lida por afásicos e } \\
\text { controles. }\end{array}$ & $\begin{array}{l}\text { Os resultados } \\
\text { são consistentes } \\
\text { com a literatura. } \\
\text { Pessoas com afasia } \\
\text { possuem menos } \\
\text { controle cognitivo } \\
\text { do processamento } \\
\text { dos recursos, por } \\
\text { isso, demonstram } \\
\text { mais prejuízo no } \\
\text { processamento de } \\
\text { frases do que os } \\
\text { controles. } \\
\end{array}$ \\
\hline $\begin{array}{l}\text { A multimodal } \\
\text { mapping study of } \\
\text { conduction aphasia } \\
\text { in impaired } \\
\text { repetititon and } \\
\text { spared Reading } \\
\text { aloud }\end{array}$ & $\begin{array}{l}\text { TOMASINO et al. } \\
(2015)\end{array}$ & $\begin{array}{l}\text { Explora a } \\
\text { neuroanatomia } \\
\text { funcional da } \\
\text { produção } \\
\text { fonológica em } \\
\text { um afásico de } \\
\text { condução após } \\
\text { cirurgia cerebral. }\end{array}$ & $\begin{array}{l}\text { Há uma } \\
\text { dissociação entre } \\
\text { duas partes do } \\
\text { fascículo arqueado, } \\
\text { mostrando que } \\
\text { este está envolvido } \\
\text { na produção } \\
\text { afásica. }\end{array}$ \\
\hline $\begin{array}{l}\text { Reading and } \\
\text { listening in people } \\
\text { with aphasia: } \\
\text { effects of syntactic } \\
\text { complexity. }\end{array}$ & DeDe (2013) & $\begin{array}{l}\text { Comparar efeitos } \\
\text { da complexidade } \\
\text { sintática em frases } \\
\text { escritas e faladas } \\
\text { para afásicos. }\end{array}$ & $\begin{array}{l}\text { Embora os efeitos } \\
\text { sintáticos foram } \\
\text { mais sentidos na } \\
\text { leitura, os afásicos } \\
\text { mostraram efeitos } \\
\text { similares aos } \\
\text { controles nas duas } \\
\text { modalidades. }\end{array}$ \\
\hline $\begin{array}{l}\text { Cognitive and } \\
\text { neural mechanisms } \\
\text { underlying reading } \\
\text { and naming: } \\
\text { evidence from } \\
\text { letter-by-letter } \\
\text { reading and optic } \\
\text { aphasia. }{ }^{4}\end{array}$ & $\begin{array}{l}\text { MARSH; HILLIS } \\
(2005)\end{array}$ & $\begin{array}{l}\text { Estudo de caso } \\
\text { com um paciente } \\
\text { de alexia sem } \\
\text { agrafia. }\end{array}$ & $\begin{array}{l}\text { É sugerida a } \\
\text { criação de um } \\
\text { modelo das regiões } \\
\text { neurais para } \\
\text { diversos processos } \\
\text { cognitivos que } \\
\text { envolvem a leitura. }\end{array}$ \\
\hline
\end{tabular}

\section{Discussão: as múltiplas facetas da leitura e da afasia}

Na presente revisão bibliográfica, é importante salientar que diversas outras maneiras são possíveis para a realização desta pesquisa, por exemplo, mudar os indexadores, restringir ou ampliar as bases 4 Este texto não trata de afasia especificamente. Ele foi incluído na amostragem porque aborda temas frequentes na pesquisa em afasia. 
v. 6 (2) $370-390$ jul/dez 2016

de dados, aumentar ou diminuir o número de idiomas dos artigos publicados, ampliar ou diminuir a faixa temporal, filtrar por local ou revista/jornal de publicação, enfatizar os diferentes métodos utilizados, procurar por produções de linguistas etc. Portanto, o intuito, a partir dessa seleção de materiais, é discutir a respeito do que foi encontrado.

De acordo com os resultados e conclusões apresentadas, podese redistribuir a discussão em forma de diferentes facetas: terapia, produção oral, mapeamento neural, complexidade linguística da leitura e, por último, mecanismos cognitivos. A categoria terapia inclui os textos que investigam, avaliam, validam algum tipo de bateria ou fazem uma discussão abrangente acerca dos procedimentos da terapia. A produção oral refere-se àquelas pesquisas que abordam a leitura em voz alta, por conseguinte, as dificuldades que subjazem à produção oral afásica. $\mathrm{O}$ mapeamento neural tem por objetivo categorizar aquelas investigações que almejam localizar funções/ descrever processos neuronais relativos à leitura. A complexidade linguística da leitura abarca todas aquelas pesquisas que trabalham com leitura silenciosa diretamente. Por fim, os mecanismos cognitivos são comumente abordados, em especial a memória de trabalho, memória de curto prazo, atenção e funções executivas, pois parecem ficar limitados após a ocorrência do AVE.

\section{Terapia}

Os textos Introdução da comunicação suplementar e alternativa na terapia com afásicos, Aplicação do teste M1-Alpha em sujeitos normais com baixa escolaridade: estudo piloto e o artigo Text level reading comprehension in aphasia: What do we know about therapy and what do we need to know? discorrem sobre alternativas terapêuticas para afásicos. É interessante salientar que todos esses textos foram produzidos por fonoaudiólogos, portanto, muito do que é focado são novas diretrizes para o tratamento de reabilitação dos pacientes. Os estudiosos dessa área costumam atentar para técnicas de treinamento específico para a dificuldade de cada paciente. Alguns destinam suas pesquisas como se fossem manuais de aplicação. Um exemplo disso é a primeira investigação (GALLI; OLIVEIRA; DELIBERATO, 2009). A pesquisa almejava descrever o uso da comunicação suplementar como uma alternativa associada a outras modalidades de linguagem (escrita, gestos), a partir do relato de dois casos de afasia.

As autoras destacam as características dos casos de afasia. 
Na maioria dos casos, há manifestações associadas às afasias, tais como: comprometimentos visuais, auditivos, paralisias ou paresias de membros superiores e/ou inferiores, quadros de disartria e/ou apraxia, disfagia ${ }^{5}$, problemas emocionais e sociais. As alterações na fala exigem, ainda, um diagnóstico diferencial entre disartria, dispraxia e distúrbios de fluência. Num estudo com 192 pacientes neurológicos, 70\% eram afásicos, 6\% com disartria e apraxia, 17\% com alterações funcionais de comunicação e $7 \%$ eram normais. Portanto, essas definições são necessárias para a postura das fonoaudiólogas. Os resultados apontam que, nesses casos, a comunicação suplementar e alternativa foi um apoio para a oralidade, leitura e escrita dos pacientes. É destacado que a implantação da comunicação suplementar deve ocorrer no diálogo e, ainda, ser um suporte para a escrita e a leitura. Além disso, os símbolos evidenciaram as dificuldades linguísticas dos pacientes, as quais estavam encobertas pela ausência da fala.

O texto Aplicação do teste M1-Alpha em sujeitos normais com baixa escolaridade: estudo piloto (ORTIZ; COSTA, 2011) é interessante porque é de autoria de um dos maiores nomes dos estudos em afasia no Brasil: Karin Zazo Ortiz. Ela é fonoaudióloga e almejou encontrar alguma variável dependente de escolaridade, fator que facilitaria os estudos no país, visto que aqui a maior parte da população no Atendimento Único de Saúde possui escolaridade baixa. A pesquisa verifica o desempenho de sujeitos normais com baixa escolaridade no teste M1-Alpha e obtém parâmetros que possam ser utilizados na avaliação clínica de pacientes afásicos com baixa escolaridade. O grupo de pesquisadores observou que a baixa escolaridade influencia o desempenho dos indivíduos nas tarefas de escrita copiada, ditado, leitura em voz alta e compreensão escrita. No entanto, como é um estudo piloto, há muito o que ser melhorado. Ele evidenciou a necessidade de revisão da pontuação do instrumento. Isso poderá originar melhora na avaliação quali-quantitativa, quando houver a reutilização do teste.

$\mathrm{O}$ artigo Text level reading comprehension in aphasia: What do we know about therapy and what do we need to know? (WEBSTER et al., 2013) evidencia a compreensão da leitora na terapia. Enquanto há estudos investigando o tratamento da leitura de palavras soltas e um número limitado de estudos almejando a leitura de parágrafos e texto conectado, motora, atrapalhando movimentos coordenados como marcha e escrita; disfagia: dificuldade na deglutição. 
v. $6(2)$

$370-390$

$\mathrm{jul} / \mathrm{dez}$

2016

poucos investigam a efetividade de cada abordagem terapêutica para a leitura de parágrafos. Ele trata de uma crítica ao aceite das terapias passivamente. Através da análise de vários estudos de caso, eles sugerem que os resultados de todos os métodos devem ser levados em conta para a reutilização desses. É também importante avaliar a melhora do comportamento do paciente em relação à leitura, da leitura em si e de como o indivíduo se sente em relação à leitura. Esse tipo de estudo é importante em todas as áreas, porém ele não comentou sobre a importância da contribuição dos linguistas na confecção dessas abordagens. Hoje há uma maior dedicação por parte de estudiosos de outras áreas, que não de Letras e Linguística, na investigação dos fenômenos linguísticos atinentes à afasia, como fonoaudiólogos e neuropsicólogos. Assim, urge um olhar mais atento de linguistas, os quais, munidos de um aparato teórico aprofundado e abrangente, podem contribuir para uma melhor compreensão do fenômeno, auxiliando também na questão da reabilitação da linguagem e consequente reintegração do sujeito aos seus grupos sociais e de trabalho.

Produção Oral

A produção oral afásica ou a dificuldade que os afásicos têm em produzir oralmente é amplamente o sintoma mais visto e investigado na afasia. Entretanto, dentre os artigos pesquisados, nenhum trata da produção oral especificamente. Existe um fator prevalente na produção oral que afeta as outras habilidades: a anomia. A anomia estigmatiza e frustra o paciente e prejudica a leitura.

Sendo a anomia tão frequente entre os afásicos, os pacientes devem ser avaliados quanto à sua capacidade de nomear objetos. Tal avaliação informará sua acurácia na nomeação, o padrão de pontos fortes e fracos, os tipos de erros produzidos por eles e sua capacidade de responder às pistas fornecidas ${ }^{6}$, permitindo formular hipóteses a partir do desempenho do paciente: quais efeitos têm, aspectos como a frequência, a extensão das palavras, a familiaridade, a animacidade e a concretude sobre a acurácia na nomeação, sobre os tipos de erros cometidos ao executar tarefas e sobre a comparação do desempenho nas diferentes tarefas e modalidades (input visual ou auditivo).

Segundo Laine e Martin (2006), tanto pessoas saudáveis quanto 6 Na maioria das vezes, a terapia consiste em fornecer pistas fonológicas para facilitar a recuperação das palavras, principalmente no caso de anomia fonológica (VITALI et al., 2007). 
afásicas cometem erros de ordem semântica e fonológica ao nomearem objetos. No entanto, a proporção de cada tipo de erro pode não ser a mesma para pessoas normais e afásicas. No caso da anomia, os erros produzidos são predominantemente semânticos ou configuram-se em substituições de palavras de natureza fonológica.

Dentre as manifestações da anomia de ordem semântica, pode haver comprometimentos semântico-sintáticos de categoria específica (e.g., abstrato vs. concreto; animado vs. inanimado) ou de classe específica de palavras (e.g., substantivos vs. verbos; palavras de função vs. palavras de conteúdo). Há ainda comprometimentos morfológicos (e.g., palavras compostas; derivações; flexões) e déficits semânticos de categoria específica (e.g., animal vs. vegetal vs. artefatos) na produção de palavras.

No caso da anomia fonológica, pode haver comprometimento no acesso ao output do sistema léxico-semântico, além da montagem desordenada de fonemas (parafasias), podendo aparecer durante a repetição de palavras, leitura oral ou nomeação de figuras. É difícil compreender os mecanismos por trás dos déficits na organização da sequência de fonemas. Tais déficits na produção de palavras em nível pós-lexical são classificados como desordens fonêmicas ou fonéticas. As desordens fonêmicas compreendem as substituições, adições, trocas e omissões de fonemas ou de combinações de fonemas presentes no output. Já as fonéticas compreendem os déficits de nível mais baixo no planejamento articulatório das sequências de som da fala que podem levar também a fonemas distorcidos. É o caso da apraxia da fala, que envolve uma variedade de anormalidades. Entre essas, estão a inconsistência nos movimentos articulatórios, a desaceleração da fala acompanhada de alongamento em segmentos e transições segmentares, padrões de tonicidade desviante, erros de vocalização e coarticulação reduzida (LAINE; MARTIN, 2006).

Especificamente em relação ao tratamento da anomia na afasia, uma vez que os casos puros de anomia específica são relativamente raros e os pacientes afásicos geralmente têm múltiplas deficiências que afetam simultaneamente vários subprocessos de nomeação e também outros aspectos da linguagem, cabe desenvolverem-se avaliações que permitam diagnosticar quais são de fato os comprometimentos linguísticos em cada paciente (LAINE; MARTIN, 2006).

Ao avaliar a anomia, características como idade, escolaridade, estado geral de saúde, nível de desempenho cognitivo pré-mórbido, 
v. $6(2)$

$370-390$

jul/dez

2016

histórico linguístico e cultural dos pacientes, bem como características das lesões em termos de localização e severidade devem ser consideradas.

\section{Mapeamento neural}

Muitos dos textos selecionados abordam uma perspectiva localizacionista, em que há uma tendência a tentar localizar as regiões ativadas de acordo com cada tarefa que o cérebro executa. Com todos os recursos de imageamento cerebral existentes atualmente, há que se considerar as regiões envolvidas na compreensão leitora de afásicos e de indivíduos saudáveis. É importante ainda verificar os locais preservados, considerando os corticais tanto quanto os subcorticais, uma vez que é sabido que tanto áreas do córtex quanto da matéria branca são importantes no que tange ao processamento da linguagem. Os estudos mais clássicos sobre as áreas da linguagem no cérebro apontam que as mais importantes estão alocadas nos córtices frontal inferior (área de Broca) e temporal (área de Wernicke), com dominância do hemisfério esquerdo (DEHAENE, 2012; FERSTL, 2007). A literatura atual sugere que há outras áreas cerebrais que exercem função linguística, como é o caso dos feixes de fibras que conectam essas áreas. Elas estão ligadas através de duas vias: dorsal e ventral, as quais desempenham mais de uma função, por exemplo, a via dorsal está envolvida no processamento sintático, particularmente na complexidade das sentenças (FRIEDERICI, 2012). É possível separá-la em duas vias: uma que conecta o córtex temporal ao córtex pré-frontal através do córtex parietal inferior e partes do fascículo longitudinal superior e a outra que interliga o córtex temporal à área de Broca através do fascículo arqueado (FRIEDERICI, 2012). A via ventral também parece ser responsável por mais de uma função. Ela auxilia no mapeamento do som e do significado bem como no processamento sintático. Considerando a complexidade de regiões cerebrais envolvidas no processamento linguístico no nível da compreensão de leitora e auditiva, assim como na produção de linguagem, é possível afirmar que existe um processo dinâmico subjacente a essa atividade e que muitas de suas facetas ainda precisam ser investigadas.

\section{Mecanismos cognitivos}

Há uma tendência a avaliar a afasia juntamente com outros construtos cognitivos, como atenção, memória de trabalho e funções executivas em geral. As funções executivas são especialidades do lobo 
frontal, região em que, coincidentemente, está localizada a área de Broca, responsável pela fala. As funções são processos cognitivos de controle e integração com objetivos de execução de tarefas específicas, precisando, de fato, dos subcomponentes desse sistema, como programação e planejamento de sequências, inibição de processos e informações concorrentes e monitoramento. As funções executivas envolvem ainda o planejamento das tarefas envolvidas para a realização de um objetivo, além de contarem com a coordenação de três funções cognitivas importantes: memória de trabalho, atenção e controle inibitório (KRISTENSEN,2006).

O cérebro guarda bilhões de impressões, algumas fugazes, outras durante a vida inteira. Chamamos essas impressões de memória. É a memória que forma a personalidade do ser humano. Afinal, memória é a aquisição, a formação, a conservação e a evocação de informações (IZQUIERDO, 2002). É uma importante faculdade cognitiva que abrange o arquivo e a recuperação de experiências. É por causa dela que se retém parte do que se aprende. Aquela que retém informações por segundos é a memória de trabalho. Todavia, não existe uma única maquinaria cerebral que seja responsável pela formação, retenção e evocação das informações aprendidas. Existem várias redes neurais com milhões de interconexões que subjazem aos processos de aprendizagem e que podem ser danificadas no AVC. Obviamente, os mecanismos utilizados pelos cérebros de todos os mamíferos são os mesmos, o que difere o ser humano dos demais é justamente a complexidade de suas memórias (IZQUIERDO, 2002). No entanto, como a memória é um sistema dinâmico, os eventos são passíveis de esquecimento, demonstrando que, em muitos casos, a retenção não é estável, por essa razão, os fonoaudiólogos apontam a queda na eficiência da memória de trabalho como uma limitação advinda da afasia.

A atenção é um construto multidimensional que se constitui de processos que focam, selecionam, dividem, mantém e inibem um comportamento (PARASURAMAN; DAVIES, 1984, apud ROGERS; FISK, 2001). Como exemplo, quando uma pessoa se encontra em uma festa, tem-se o efeito coquetel. Há ruído, variedade de estímulos sensoriais, mas a pessoa é capaz de selecionar um pequeno conjunto de estímulos e manter-se atento a eles, direcionando sua atenção de acordo com sua preferência. Esse fato possibilita que o indivíduo converse com uma outra pessoa à medida que os demais estímulos ambientais estão ocorrendo e, em boa parte, sendo ignorados. Segundo estudiosos da 
v. $6(2)$ $370-390$ $\mathrm{jul} / \mathrm{dez}$ 2016

área, quando os indivíduos envelhecem, a dificuldade em manter-se atentos aumenta, bem como a facilidade de distração para informações irrelevantes, causando prejuízos no desempenho das funções executivas (BRUCKI, 2004; CABEZA, 2004). De fato, idosos queixam-se de que custam a lembrar-se de determinadas informações por causa dessa queda na atenção e porque ela também está intimamente relacionada à memória (NAHAS; XAVIER, 2006). Infelizmente, grande parte da literatura as trata como processos distintos. Os artigos lidos apontam o tratamento da atenção como uma estratégia para um aprimoramento das técnicas para tratamento da afasia.

O controle inibitório é aquele que suprime ou inibe a resposta automática quando um estímulo é oferecido. Ao lidar com tarefas que exijam formular um objetivo, principalmente se forem tarefas novas, planejamento e escolha entre as alternativas de comportamento para se alcançar o objetivo, comparar probabilidades de sucesso e eficiência são fatores em que o controle executivo é indispensável (RABBITT, 1996). Além disso, ele também é responsável por interromper uma resposta em curso, mesmo ela não sendo efetiva, fato que permite uma reavaliação da atitude usada. Por último, ele inibe as informações que estão em cooperação, permitindo o desempenho de uma delas. Indivíduos que sofreram AVE apresentam também problemas de controle. Portanto, uma vez tratadas as funções executivas no todo, maior é a possibilidade de reabilitação do paciente.

\section{Considerações finais}

A partir da breve revisão, pode-se concluir que ainda é indispensável o aumento das pesquisas no Brasil, particularmente no que tange à leitura e à afasia. É importante investigar, em um contexto brasileiro, falantes da nossa língua, pouco escolarizados, juntamente com especialistas com formação no país. Até agora, foi visto que há cada vez mais alternativas para auxílio nas terapias e uma tendência a utilizar exames de neuroimagem para correlacionar áreas lesionadas e performances dos indivíduos, demonstrando, através dessas facetas, a versatilidade e possível interdisciplinaridade do tema. É imprescindível uma ciência que veja todas essas facetas do distúrbio, como a médica, cognitiva, neuropsicológica, neurológica, fonoaudiológica, linguística e farmacológica. Para isso, é evidente que diversas áreas precisam dialogar mais sobre o tema. 


\section{Referências}

AKBARI, M. A Multidimensional Review of Bilingual Aphasia as a Language Disorder. Advances in Language and Literary Studies, v. 5, n. 2, p. 73-86, 28 abr 2014.

BALASUBRA MANIAN, V.; COSTELLO, M. Oral Reading and Writing in Broca's Aphasia: Implications for the Common and Independent Lexicon Theories. Procedia - social and behavioral sciences, vol. 23, p.78-79, December 2011. DOI: 10.1016/j.sbspro.2011.09.178

BREE, E.; JANSE, E.; VAN DE ZANDE, A.M. Stress assignment in aphasia: word and non-word reading and non-word repetition. Brain Lang. Dec., vol.103. $\mathrm{n}^{\mathrm{o}}$ 3, p.264-75, 2007. DOI: 10.1016/j.bandl.2007.07.003

BRUCKI, S. M. D. Envelhecimento e memória. In: ANDRADE, V.M, SANTOS, F. H. dos, BUENO, O. F. A.(orgs) Neuropsicologia hoje. São Paulo: Artes Médicas, 2004, p. 389-402.

CABEZA, R. Redução da assimetria hemisférica em adultos mais velhos: o modelo HAROLD. In: ANDRADE, V.M, SANTOS, F. H. dos, BUENO, O.F.A.(orgs) Neuropsicologia hoje. São Paulo: Artes Médicas, 2004. p. 420-454.

CHESNEAU, S.; SKA, B. Text comprehension in residual aphasia after basiclevel linguistic recovery: a multiple case study. Aphasiology, vol. 29, $\mathrm{n}^{0} 2$, p.237-256, February 2015. DOI: 10.1080/02687038.2014.971098

DEDE, G. Reading and listening in people with aphasia: Effects of syntactic complexity. American Journal of Speech-Language Pathology, v. 22, n. 4, p. 579-590, 2013.

DEHAENE, S. Os neurônios da leitura. Porto alegre: Penso, 2012.

FERSTL, E. C. et al. The extended language network: a meta-analysis of neuroimaging studies on text comprehension. Human brain mapping, v. 29, n. 5, p. 581-93, 2007/8.

FRIEDERICI, A. The cortical language circuit: from auditory perception to sentence comprehension. Trends in Cognitive Sciences, v. 16, n 05, p.262268, 2012.

GALLI, J.F.M; OLIVEIRA, J. P.; DELIBERATO, D. Introdução da comunicação suplementar e alternativa na terapia com afásicos. Rev Soc Bras Fonoaudiol. Vol.14, no 3, p.402-10, 2009.

GERNSBACHER, M. A. Language comprehension as structure building. Oregon: Psychology Press, 1990.

GREEN, D. Regulating the bilingual lexico-semantic system. University College London, 1998.

GREEN, J. Neupsychological evaluation of the older adult: a clinician's guidebook. San Diego: Academic Press, 2000.

IZQUIERDO, I. Memória. Artmed: Porto Alegre, 2002. 
V. 6 (2)

370-390

$\mathrm{jul} / \mathrm{dez}$

2016

KANDEL, E.; SHWARTZ, J.; JESSEL, T. Princípios de neurociências. $3^{\mathrm{a}}$ ed. Brasil: MCGRAW-HILL BRASIL, 2000.

KAY, J., LESSER, R., COLTHEART, M. Psycholinguistic Assesments of Language Processing in Aphasia. Hove: Lawrence Erlbaum Associates Ltd, 1992.

KIM, E., BOLGER, P., Examining the facilitative effect of semantic context on sentence Reading in aphasia using Eye-tracking, Procedia Social and Behavioral Sciences, v 61, p. 58-59, 2012.

KRISTENSEN, C. H. Funções executivas e envelhecimento. In: PARENTE, $M$. A. de M. P.(org). Cognição e envelhecimento. São Paulo: ARTMED, 2006. p. 97-113.

LAINE, M.; MARTIN, N. Cognitive Models of Lexical Retrieval. In: LAINE, M.; MARTIN, N. Anomia: Theoretical and Clinical Aspects. New York: Psychology Press, 2006. Cap. 2.

LEE, J.B.; SOHLBERG, M. Evaluation of attention training and metacognitive facilitation to improve reading comprehension in aphasia. Am J Speech Lang Pathol. May, vol. 22, no 2, S318-33, 2013 DOI: 10.1044/1058-0360(2013/120099.

LIMA, F. A. F. Correlação Entre Os Achados De Uma Avaliação De Linguagem E Fala No Leito E O Território Vascular Encefálico Em Pacientes Vítimas De Ave Em Estado Agudo. [Trabalho de Conclusão de Curso] Universidade Federal de Minas gerais, Belo Horizonte, 2009. 55 pgs.

MANSUR, L. L. et al. Descriptive study of 192 adults with speech and language disturbances. São Paulo Medical Journal = Revista Paulista de Medicina, V. 120, n. 6, p. 170-174, 2002.

MARSH, E.B.; HILLIS, A.E. Cognitive and neural mechanisms underlying reading and naming: evidence from letter-by-letter reading and optic aphasia. Neurocase, Oct, vol.11, nº 5, p.325-37, 2005. DOI: 10.1080/13554790591006320

McNeil, M. R.,PRESCOTT, T.E. The revised token test. Austin: PRO ED, 1978.

McNeil, M.R., PRATT, S.R., SZUMINSKY, N., SUNG, J.E., FOSSETT, T.R.D., FASSBINDER, W., LIM, K.Y. Reliability and validity of the computerized revised token test: comparison of reading and listening versions on persons with and without aphasia. Journal of Speech, Language and Hearing Research. vol 58, $311-324,2015$.

METEYARD, L. et al. Profiling text comprehension impairments in aphasia. Aphasiology, v. 29, n. 1, p. 1-28, 2014.

MOINEAU, S., DRONKERS, N., BATES, E. Exploring the processing continuum of single-word comprehension in aphasia. Journal of Speech, Language and Hearing Research, vol 48, 884-895, 2005.

MORATO, E. M. Neurolinguística. In: MUSSALIN, F.; BENTES, A.C. (Org). Introdução à linguística: domínios e fronteiras. 8 ed. São Paulo: Cortez, v. 2 p. 167-200, 2012. 
NAHAS, T. R.; XAVIER, G. F. Atenção: Mecanismos e desenvolvimento. In: MELLO, C.B., MIRANDA, M.C., MUSZKAT, M. Neuropsicologia do desenvolvimento: conceitos e abordagens. São Paulo: Memnon, 2005. p 4675 .

ONTKO, E. et al. A neurolinguistic analysis of neologisms in reading. Brain and Language, vol. 95, $\mathrm{n}^{0} 1, \mathrm{p} .42-43$, October 2005. DOI: $10.1016 / \mathrm{j}$. bandl.2005.07.015

ORTIZ, K.Z. Afasia. In: ORTIZ, K.Z. (Org.) Distúrbios neurológicos adquiridos. $2^{\mathrm{a}}$ ed. São Paulo: Manole, 2010.

ORTIZ, K.Z.; COSTA, F.P. Aplicação do teste M1-Alpha em sujeitos normais com baixa escolaridade: estudo piloto. J. Soc. Bras. Fonoaudiol. vol.23 no.3 São Paulo July/Sept. 2011. http://dx.doi.org/10.1590/S2179-64912011000300007

PARASURAMAN, R.; DAVIES, D. R. apud ROGERS, W. A.; FISK, A. D. Understanding the role of attention in cognitive aging research. Handbook of the psychology of aging. Birren, J. E.; Schaie, K. W. Academic Press: USA, 2001.

PURDY, M, NEWMAN, D. Comparison of Reading performance in fluente and non-fluent aphasia. Procedia Social and Behavioral Sciences v 23, 80-81, 2011.

RABBITT, P. Introduction: methodologies and models in the study of executive function. In: RABBITT, P. (org) Methodology of frontal and executive function. East Sussex: Psychology Press, 1996. p 1-38.

SANTOS, M. D., MAC-KAY, A.P.M.G., GAGLIARDI, R. J. Study on language comprehension in aphasic subjects. 2008. In: dialnet.unirioja.es/descarga/ articulo/4002651.pdf. Acesso em 04/06/2015.

SCHWARTZ, M. F. Patterns of speech production deficit within and across aphasia syndromes: Application of a psycholinguistic model. In M. Coltheart, G. Sartori, \& R. Job (Eds.), The cognitive neuropsychology of language. Hove: Lawrence Erlbaum Associates Ltda: 1987. p. 163-199.

SHALLICE, T. From neuropsychology to mental structure. New York: Cambridge University Press, 1988

SPRINGER, L. Therapeutic approaches in aphasia rehabilitation. In: STEMMER, B.; WHITAKER, H.A. et al. Handbook of neuroscience of language. 1a. ed. Academic Press: 2008. p. 397-406.

STEMMER, B.; WHITAKER, H.A. et al. Handbook of neuroscience of language. 1a. ed. Academic Press: 2008.

SUNG, J. et al. Real-time processing in reading sentence comprehension for normal adult individuals and persons with aphasia. Aphasiology, vol. 25, $\mathrm{n}^{\mathrm{O}} 1$, p.57-70, January 2011. DOI: 10.1080/02687031003714434

SZELAG, E., LEWANDOWSKA, M., WOLAK, T., SENIOW, J., PONIATOWSKA, R., POPPEL, E., SZYMASZEK, A. Training in rapid auditory processing ameliorates auditory comprehension in aphasic patients: A randomized controlled pilot study. Journal of Neurological Sciences.v 338, p.77-86, 2014. 
V. 6 (2) $370-390$ $\mathrm{jul} / \mathrm{dez}$ 2016
TOMASINO, B. et al. A multimodal mapping study of conduction aphasia with impaired repetition and spared reading-aloud. Neuropsychologia, V. 70, p. 214-226, 2015.

VITALI, P. et al. Training-induced brain remapping in chronic aphasia: a pilot study. Neurorehabil Neural Repair. vol 27, no 21, p.152-160, 2007.

WEBSTER, J. et al. Text level reading comprehension in aphasia: What do we know about therapy and what do we need to know? Aphasiology, v. 27, n. 11, p. $1362-1380,2013$.

ZIPSE, L., KEARNS, K., NICHOLAS, M., MARANTZ, A. A MEG investigation of single-word auditory comprehension in aphasia. 2011. Journal of Speech, Language and Hearing Research. Vol 54, p.1577-1596, 2011.

Recebido em: 01 de ago. de 2016.

Aceito em: 27 de dez. de 2016. 